\title{
Solvency Assessment for Insurance Groups in the United States and Europe-A Comparison of Regulatory Frameworks
}

\section{Caroline Siegel}

Institute of Insurance Economics, University of St. Gallen, Tannenstrasse 19, St. Gallen CH 9000, Switzerland.

As a reaction to the increasing trend of insurers forming and participating in financial conglomerates and insurance groups, supervisory authorities are currently developing groupwide solvency regulations. The International Association of Insurance Supervisors (IAIS) recently published an issues paper that discusses the challenges to group supervision and defines criteria for a thorough group solvency framework. Based on these criteria, this article provides an overview and comparison of three important approaches - the U.S. solo-plus approach of the National Association of Insurance Commissioners, Switzerland's group structure model and the Solvency II Directive on Group Solvency Assessment. The analysis reveals various deficits within the group regulation of the United States implying the need for future regulatory work. By contrast, the performance of the European frameworks with regard to the IAIS criteria is good. In particular, the Swiss framework can be seen as a prime example of an innovative and solid group solvency assessment.

The Geneva Papers (2013) 38, 308-331. doi:10.1057/gpp.2013.3

Keywords: group supervision; insurance group; regulation; risk-based capital; Solvency II; Swiss Solvency test

Article submitted 22 February 2012; accepted 14 January 2013; published online April 2013

\section{Introduction}

Today, most internationally operating insurance companies are organised in financial conglomerates or insurance groups. As a result, over the past decade, many countries have set up additional regulatory frameworks that are applied on the group level. This group-wide solvency assessment, however, does not replace the regulation for individual legal entities within the group. They are rather meant to supplement the solo supervision, which remains a key tool to provide for policyholder protection. ${ }^{1}$

The interactions of the legal entities within an insurance group may have a substantial impact on the group's solvency as well as the risks to the financial sector as a whole. In order to set incentives for a solid enterprise risk management and a groupwide capital management that complements risk management at the solo level, establishing appropriate group-wide capital standards is of vital importance.

The International Association of Insurance Supervisors (IAIS) has therefore set out principles on group-wide supervision as an internationally applicable guidance for the

\footnotetext{
${ }^{1}$ IAIS (2009b).
} 
establishment of consistent and effective group-wide supervision. These principles include $^{2}$ :

- A group-wide capital adequacy assessment by applying either an aggregation method, a consolidated approach or a legal-entity approach.

- An assessment of the propriety of the senior management and significant shareholders of the insurance group.

- An adequate group-wide risk management to enhance internal controls on the sololevel.

- A supervisory authority that has enough power to adequately supervise the whole group.

- Arrangements to allow supervisors to cooperate and exchange information about the insurance group across borders.

Based on these principles, the IAIS's issues paper explores different issues and challenges associated with group supervision and provides an analysis of possible approaches. ${ }^{1}$ This has encouraged us to extend the contribution of the IAIS by conducting a comparison of three current group solvency approaches, based on the different challenges associated with a risk-sensitive group-wide solvency assessment (see Section "Comparison").

Within the recent literature on insurance regulation, Eling and Holzmüller ${ }^{3}$, Cummins and Phillips ${ }^{3}$ as well as Holzmüller ${ }^{4}$ carry out comparisons of different solo capital standards. Eling and Holzmüller ${ }^{5}$ provide an overview and comparison of the solo-level risk-based capital charges of the United States, New Zealand, as well as the European Union and Switzerland, whereas Cummins and Phillips and Holzmüller ${ }^{6}$ base their analyses on the implications of the U.S. risk-based capital approach, Solvency II and the Swiss Solvency Test (SST). Furthermore, Vaughan ${ }^{7}$ compares Solvency II to the U.S. regulatory system and analyses the enhancement potential of the latter. However, all papers mentioned above do not focus on the consideration of group solvency issues.

In fact, current literature on insurance group solvency assessment is rather scarce. Within the context of the SST, Filipovic and Kupper, Keller and Luder ${ }^{8}$ present the Swiss group structure model ${ }^{9}$ and examine optimal capital and risk transfer and its implications on group diversification. The paper by van Rossum ${ }^{10}$ examines the changes in the insurance industry, such as the emergence of financial groups, and the alignment of its regulatory frameworks to those of the banking industry. Furthermore,

\footnotetext{
${ }^{2}$ IAIS (2008b).

${ }^{3}$ Eling and Holzmüller (2008); Cummins and Phillips (2009).

${ }^{4}$ Holzmüller (2009).

${ }^{5}$ Eling and Holzmüller (2008).

${ }^{6}$ Cummins and Phillips (2009) and Holzmüller (2009).

${ }^{7}$ Vaughan (2009).

${ }^{8}$ Filipović and Kupper (2007, 2008); Keller (2007); Luder (2007).

${ }^{9}$ Pfeiffer (2008).

${ }^{10}$ van Rossum (2005).
} 
Darlap and Mayr $^{11}$ consider important challenges to group supervisors under the Solvency II Directive. ${ }^{12}$ The authors argue that there are several risks specific to financial conglomerates and insurance groups that are not covered by modern portfolio theory, such as concentration risks and financial contagion, and recommend the introduction of copula-based solvency models. ${ }^{11}$

Our paper presents an outline and comparison of three current group solvency approaches: the solo-plus approach ${ }^{13}$ of the National Association of Insurance Commissioners (NAIC), the group structure model of the Swiss Solvency Test and the group capital assessment of the Solvency II Directive. The U.S. and the European approaches were selected because of their international importance, whereas the group structure model of Switzerland was included because it is currently regarded as one of the most innovative group solvency frameworks. The comparison is based on five different issues and challenges that are provided by the IAIS's issues paper, ${ }^{1}$ usually associated within the discussion of a risk-sensitive group-wide solvency assessment of insurance companies.

The paper is structured as follows: the next section provides the overview of the three group solvency models. The comparison, the main part of the paper, is conducted in the subsequent section. The final section concludes and evaluates the three group solvency approaches.

\section{Assessing group solvency: An overview}

Typically there are two different approaches according to which a group solvency assessment can take place. The IAIS's issues paper refers to them as approaches with a legal entity perspective and approaches with a consolidated viewpoint. ${ }^{1}$ A legal entity approach regards the group as an accumulation of separate legal entities that are interdependent from each other. Here, the capital requirements and risks of each group member are aggregated, taking intra-group transfers into account. By contrast, a consolidated group model regards the insurance group as one single entity and focuses on the operational and managerial structure of the group as a whole. Usually, a capital requirement for the group is calculated, on the basis of consolidated accounts. Ideally, a solid group model should consider an appropriate balance between the two perspectives. By including advantages of both approaches, the group model is able to appropriately treat insurance groups according to their level of integration regarding the control of the parent company, operations, internal risk management and capital allocation. ${ }^{14}$

This section presents a description of the three regulatory frameworks under consideration, beginning with a general discussion of each. Afterwards, an overview of the group approaches of each framework is conducted.

\footnotetext{
${ }^{11}$ Darlap and Mayr (2006).

${ }^{12}$ EC (2009).

13 NAIC (2010c).

${ }^{14}$ For more details refer to IAIS, 2009b.
} 


\section{Solo-plus approach of the NAIC}

The NAIC risk-based capital system was introduced in 1994 and constituted by that time one of the first capital standards to incorporate an insurance company's risk exposition to assess capital requirements. It determines solvency through a twocomponent approach: ${ }^{15}$

The first component is a factor-based formula specific for each insurance type (life, health and property/casualty insurance) that calculates the required "risk-based capital" (RBC), a required minimum capital level. The RBC is compared with the "total adjusted capital" (TAC), an insurer's available amount of capital (including surplus). The capital charges depend upon different risk-factor charges, which are multiplied by several financial statement magnitudes of the insurer. Subsequently, a covariance calculation leads to the final adjusted RBC.

The second component is a law that identifies five levels of regulatory intervention. This rules-based component defines the level of supervisory action based on the quotient of the total adjusted capital over the risk-based capital $(T A C / R B C)^{15}$ : The first level represents a ratio of $(T A C / R B C) \geqslant 200$ per cent implying no regulatory intervention. A solvency quotient between 150 and 200 per cent, the "company action level", results in the regulatory requirement of an additional report that comprises a financial plan of how to address the undercapitalisation of the company. The "regulatory action level" involves a solvency ratio between 100 and 150 per cent. Apart from the required additional report, this level triggers the intervention of the insurer's assigned state commissioner. The "authorised control level" (70 per cent $\leqslant(T A C / R B C)<100$ per cent $)$ involves the adoption of control over the company by the regulator. Finally, a solvency ratio of less than 70 per cent triggers "mandatory control" by the regulator.

Regarding the qualitative solvency assessments, the NAIC has only started to set up guidelines in 2011 (the so-called "High-Level Corporate Governance Principles") with respect to internal risk management, control and corporate governance. These guidelines constitute general principles that request, for example: ${ }^{16}$

- A sound corporate governance framework, including an effective internal control system. In this context, the insurance commissioner has the power to require a demonstration of the adequacy of the framework and can demand changes to improve it.

- The effective oversight of the governance by the board of directors.

- A reliable reporting process of the financial health and solvency of the insurance company.

- A risk management system that is able to properly identify, assess, report and manage the risks.

As pointed out by the NAIC, the current U.S. regulatory system for insurance groups can be described as a solo-plus regime. It belongs to the class of legal-entity approaches as it utilises an aggregation method for the group adjustments. ${ }^{13}$ That is, the solvency assessment is based on the single legal entity but is adjusted for intra-group

\footnotetext{
${ }^{15}$ NAIC (2009c).

${ }^{16}$ NAIC (2011e).
} 
transactions. ${ }^{17}$ This means, inter alia, that the regulatory control levels of intervention are left within the single entity. ${ }^{13}$ In addition, insurance groups are obliged to submit an annual report on the ultimate insurance holding company, ${ }^{1}$ and regulators are required to consider group capital risks during their annual review process. ${ }^{17}$

The NAIC's approach to group supervision is currently regulated through the Insurance Holding Company System Regulatory Act (Model \#440) and the Insurance Holding Company System Model Regulation with Reporting Forms and Instructions (Model \#450). ${ }^{18,19}$ The models define an insurance group as a so-called "insurance holding company system", which is comprised of two or more affiliated organisations or legal persons of which at least one has to be an insurance company. ${ }^{19}$ They require disclosure of relevant information on the change in control of an entity, mergers and acquisitions, material intra-group transactions, as well as information on the interrelations between affiliated insurance companies. ${ }^{20}$

As a response to the financial crisis of 2007, the NAIC initiated the Solvency Modernization Initiative (SMI) in June 2008 to revise and enhance insurance supervision as well as banking supervision and accounting standards. One of its key revision areas is the issue of insurance group regulation. In this context, the Insurance Holding Company System Regulatory Act was modified and adopted in December 2010. Its most important modifications include: ${ }^{21}$

- The requirement to disclose information on possible operations of the insurer that could potentially give rise to enterprise risk, that is operations or events which might adversely affect the financial condition, liquidity or reputation of one or more insurers of an insurance holding company system.

- The expansion of regulators' access to financial information on affiliated companies.

- The establishment of and participation in supervisory colleges.

Also, the NAIC is in the process of developing a financial analysis for holding companies, and best practices for supervisory colleges and holding company systems, as well as group capital assessments through the new "Own Risk and Solvency Assessment" tool (ORSA). ${ }^{17}$ The ORSA has two main goals: ${ }^{22}$

1. To establish guidelines for an effective enterprise risk management through which the (re)insurance companies that are part of a holding company system can identify and quantify their risk profile.

2. To establish a group-wide capital and risk assessment.

An insurance group member has to regularly conduct the ORSA to assess its solvency position and is required to document the process of solvency assessment and its results through a "high-level summary report". 22

\footnotetext{
${ }^{17}$ NAIC (2011d).

${ }^{18}$ NAIC (2010a).

${ }^{19}$ NAIC (2010b).

${ }^{20}$ NAIC (2009a).

${ }^{21}$ NAIC (2011c).

${ }^{22}$ NAIC (2011b).
} 


\section{Group structure model of the Swiss Solvency Test}

The SST was initiated by the Federal Office of Private Insurance of Switzerland in 2003 and came into effect in 2008. It is a risk-based solvency standard that incorporates both quantitative and qualitative solvency requirements, the compliance of which has to be documented in separate annual reports.

With regard to the former, an annual SST-report is requested on the overall risk situation of the insurer, based on an economic capital concept. Here, an insurance company's available economic capital (also called "risk-bearing capital" under the SST), which constitutes a financial cushion to buffer variations in assets and liabilities throughout the business year, is defined as the company's comprehensive assets minus the discounted best estimate of its liabilities. ${ }^{23}$ The SST is based on a market-consistent valuation calculating a lower capital bound, called "minimum solvency", and an upper bound, called "target capital". ${ }^{24}$ While the former is a statutory magnitude, the latter is calculated consistent with the market and is defined as the tail value at risk of the change in available economic capital plus the capital cost over a one-year time horizon. $^{23}$

An insurance company has to calculate its "SST quotient", the ratio of risk-bearing capital over the target capital. ${ }^{25}$ The three thresholds of supervisory intervention of FINMA are determined according to the value of this ratio. ${ }^{25}$ Threshold 1 is reached with an SST quotient of 100 per cent. Thresholds 2 and 3 are drawn at solvency quotients of 80 and 33 per cent, respectively. An insurer with a SST ratio above threshold 1 is regarded as sufficiently solvent and is not subject to regulatory intervention. A ratio between thresholds 1 and 2, however, triggers an intensified observation of the respective insurance company by FINMA. An insurance company with an SST quotient between 80 and 33 per cent has to submit a restructuring plan within the next two months to FINMA. Furthermore, the authorities can prohibit any risky new business and require an additional liquidity plan. An insurance company falling below threshold 3 is subject to immediate intervention by FINMA, and the insurer is forced to take immediate actions to increase the risk-bearing capital and to decrease the target capital. If FINMA finds the actions to ensure policyholder protection insufficient, it can revoke the insurer's license.

Concerning the qualitative solvency assessment in Switzerland, the risk management, internal control and corporate governance have to conform to the Swiss Quality Assessment and be documented in a risk management report. ${ }^{26}$

The SST group structure model is a supplement to the individual SST for financial conglomerates and in particular for insurance groups. It defines an insurance group as two or more undertakings that build an economic unit or are interrelated by influence or control of which at least one is an insurance company. ${ }^{27}$ The group structure model is intended to complement the solo SST by applying the same quantitative and

\footnotetext{
${ }^{23}$ FOPI (2006).

${ }^{24}$ FOPI (2004).

${ }^{25}$ FINMA (2008b).

${ }^{26}$ FOPI (2006 and 2007).

${ }^{27}$ FASC (2004).
} 
qualitative requirements to the group. With regard to the former, the methodology to quantitatively assess group solvency, the Swiss model is a legal entity approach in the sense that capital requirements are calculated for each legal entity separately, taking into account group effects such as ownership structure and capital and risk transfer instruments (CRTIs). ${ }^{1,28}$ Consequently, the methodology of the model does not lead to one single SST quotient denoting the solvency of the whole insurance group but calculates separate capital charges for each company. However, an additional solvency assessment on a consolidated basis can be required by the supervisory authority or may be granted upon application of the insurance group. ${ }^{25}$

The group-level SST is based on several general principles and assumptions, which can be summarised as follows: ${ }^{29}$

- An insurance group is considered to be a collection of different legal entities that are connected through a set of legally binding CRTIs and organised as a parentsubsidiary group structure.

- Limited fungibility ${ }^{30}$ of capital and limited transferability ${ }^{31}$ of assets and risks is assumed, meaning group effects are recognised only by taking into account the web of legally binding CRTIs. In times of financial distress, available economic capital is not transferred between the legal entities unless legally binding CRTIs are in place.

- The available economic capital of subsidiaries is defined as the entities' economic values less a market value margin, the latter being calculated via a cost of capital approach.

- When determining the SST quotient of the parent company, the economic values of its subsidiaries are taken into account as assets of the parent company.

In addition to the individual capital requirements and the inclusion of all legally binding CRTIs into the calculation of the group solvency, the Swiss framework requires a scenario analysis on the group level. Here, the effects of several possible stress scenarios on all legal entities of the insurance group as well as the expected economic loss to the group as a whole have to be quantified.

The requirements of the group structure model are satisfied when the individual SST ratios of all group members lie above 100 per cent. $^{25}$

The Swiss Quality Assessment specifically includes insurance groups and conglomerates. However, it is stated that the confirmation of an implementation by the highest group member is enough as long as it controls and monitors the other entities, subject to Swiss supervision.

\footnotetext{
${ }^{28}$ Capital and risk transfer instruments are, for example, dividends, intra-group retrocession, loans, participations, guarantees and reinsurance agreements (see, e.g., Filipović and Kupper, 2007).

${ }^{29}$ Keller (2007) and Filipović and Kupper (2007).

${ }^{30}$ According to Filipovic and Kupper (2007), "fungibility" is hereafter defined as the ability to quickly generate cash by converting transferable assets.

31 The term "transferability" in this context refers to the actual capability of transferring assets and risks from one entity of the group to another, even and especially when the group has to face financial distress in one or more entities (see IAIS, 2009b).
} 


\section{Solvency II Directive on group solvency assessment}

Solvency II is the European Commission's showcase to harmonise European insurance regulation across EU countries. From 2013 onwards, it will replace the Solvency I framework. The risk-based Solvency II system is based on three main thematic areas, the "pillars". 32

Pillar I determines quantitative capital requirements, which contains, similar to the SST, two key magnitudes that have to be calculated: the "solvency capital requirement" (SCR) and the "minimum capital requirement" (MCR). ${ }^{33}$ The SCR corresponds to the target capital of the SST and is calibrated on the basis of a value at risk concept with a confidence level of 99.5 per cent (in contrast to the tail value at risk concept with a 99 per cent confidence level under the SST). The second magnitude, the MCR, constitutes a minimum capital level below which the amount of financial resources is not supposed to fall, ${ }^{12}$ and is comparable with the minimum solvency of the SST approach. It is calculated via a linear formula with a floor of 25 per cent and a cap of 45 per cent of the SCR. ${ }^{33}$ Additionally, the regulators have defined a fixed minimum absolute floor depending on the type of insurance company. In general, the absolute floor for nonlife insurers is set to $€ 2.2$ million and $€ 3.2$ million for life insurers as well as reinsurers. ${ }^{33}$

The focus of Pillar II is on qualitative requirements regarding corporate governance, risk management and internal control. ${ }^{12}$ With regard to corporate governance this includes the requirement of a transparent organisational structure, an efficient system to transmit information, and written policies regarding internal risk management, control and audit (see Article 41 of the Solvency II Directive). Furthermore, Article 44 demands a risk management system that is able to identify, assess, report and manage the risks of the (re)insurance company on a continuous basis. As part of the risk management system, the EIOPA has set up general guidelines for the "Own Risk and Solvency Assessment". The European ORSA comprises, for example, the assessment of the "overall solvency needs" and the constant compliance with the solvency capital requirements over the undertaking's business year (see Article $45^{12}$ ).

Finally, Pillar III sets out the disclosure and transparency rules. Insurers have to annually disclose a solvency and financial report including a description of the undertaking's performance, corporate governance, risk profile and capital management (see Article $51^{12}$ ).

The Solvency II Directive on group-wide solvency assessment improves and modernises the Insurance Group Directive from 1998. ${ }^{34}$ The supplementary group supervision is applied to all (re)insurance companies that are part of a group as defined by Article $212(1){ }^{12}{ }^{12}$ That is, to all (re)insurance undertakings that are a participating undertaking in or a subsidiary of at least one (re)insurance undertaking or insurance holding company or mixed-activity insurance holding company of the European Community (see Articles 218 to 258), or a third country state (see Article 213(2) ${ }^{12}$ ). To each insurance group a group supervisor is assigned who organises supervision. ${ }^{32}$

\footnotetext{
${ }^{32} \mathrm{EC}(2011 \mathrm{~b})$.

${ }^{33}$ EC (2010).

${ }^{34} \mathrm{EC}(1998)$.
} 
With regard to the quantitative capital requirements, Solvency II determines the group SCR as well as the amount of eligible own funds on the group level. ${ }^{35}$ The group SCR is calculated on the same VAR $_{99.5}$ concept as the SCRs for the individual legal entities and equals the amount of economic capital needed to ensure the solvency of the entire group.

The group capital assessment of Solvency II tries to combine the two approaches mentioned above: the understanding of the insurance group as being a collection of separate legal entities and the integrated view of the group as one consolidated entity. ${ }^{1}$ However, due to the standard formula to assess group-wide capital requirements, and especially in comparison to the group SST and the NAIC approach, it can clearly be categorised under the models with a consolidated focus.

The standard approach to compute group solvency is the "Accounting Consolidation-Based Method". ${ }^{33}$ It calculates the group SCR on the basis of consolidated balance sheets and can be described as the consolidated solvency capital requirement $\mathrm{SCR}^{*}$ of those insurance companies for which the consideration of diversification effects is approved plus the sum of the solo SCRs of the residual group members for which diversification is not approved. ${ }^{35}$ In order to calculate the SCR*, insurance companies may apply the standard formula for solo entities to the consolidated data, as if the group were an integrated entity. ${ }^{33}$ The insurance group's solvency margin is then defined as the difference between its eligible own funds and the group SCR.

When applying the accounting consolidation-based method, a group capital floor has to be calculated. It is given by the sum of the solo MCRs (determined according to Article 129(1) and Article 129(3) of the Solvency II Framework Directive), of the participating entities, as well as the proportional share of the solo MCRs of the related entities. $^{33}$

If the group supervisor comes to the conclusion that the application of the standard method described above is not appropriate for a specific group, Article 220 of the Solvency II Directive 2009/138/EC states that an alternative method should be applied, the "Deduction and Aggregation Method". ${ }^{12}$ Under this approach, group solvency is given by the difference between the sum of the aggregated eligible own funds of all group members and the aggregated solo SCRs. ${ }^{35}$

Apart from the two methods described above, it is also possible for an insurance group to apply for permission to calculate group solvency on the basis of an internal model. ${ }^{12}$

Concerning the corporate governance, risk management and internal control mechanisms requested for the single (re)insurance company, Article 246 of the Solvency II Directive states that the same rules apply to groups. In particular, the ORSA has to be undertaken at the group level and is subject to a review by the group supervisor. ${ }^{12}$

\section{Comparison}

This section sets out a comparison of the three group solvency frameworks displayed above. We aim to contrast the three approaches with respect to several group solvency

\footnotetext{
${ }^{35}$ CEIOPS (2009a).
} 
issues identified by the Issues Paper on Group-Wide Solvency Assessment and Supervision of the IAIS $^{1}$ :

1. Assessment of risk dependencies: a group solvency approach should be able to appropriately model dependencies between different risk categories.

2. Fungibility of capital and recognition of diversification effects: the restriction in the transferability of assets and the fungibility of capital has to be modelled, and diversification effects should be adequately recognised.

3. Prevention of multiple capital gearing: a group solvency approach needs to prevent any intra-group generation of capital so that an insurance group's capital resources can be correctly compared with the group capital requirements.

4. Avoidance of regulatory arbitrage and implementation of supervisory colleges: in order to avoid regulatory arbitrage, an insurance group should be supervised under the same regulatory regime; if this is not feasible, a restriction of intra-group transfers to the entities that are subject to a different regulatory regime and close cooperation between the supervisory authorities of different jurisdictions is crucial.

5. Scope of group supervision and treatment of nonregulated entities: in order to be able to assess all relevant risks an insurance group is exposed to, a group solvency approach needs to provide adequate mechanisms to deal with nonregulated entities of a group.

\section{Assessment of risk dependencies}

The issue of how diversification effects and the pooling of risks within insurance groups should be recognised has gained additional relevance after the subprime crisis of 2007-2009. As risk dependencies typically increase in times of financial distress, the modelling of the tail characteristics of a risk category's distribution function becomes particularly important in such situations. As Embrechts et al. ${ }^{36}$ point out, the assumptions of multivariate normally distributed returns and linearly correlated risks are especially problematic in the insurance sector, due to the claims data that often exhibits skewness and fat tails.

However, former solvency models often relied on linear correlation measures and were not able to capture heavy tails. Therefore, the IAIS requires in its issues paper the standardised methods for calculating capital requirements to ensure adequate quantification of the underlying risks an insurance group is exposed to and to pay particular attention regarding the modelling of the distribution functions' tails. ${ }^{1}$

The NAIC's RBC system uses a standard formula to calculate solo capital charges that aggregates risks on the basis of a covariance adjustment to account for diversification. ${ }^{15}$ In a first step, the covariance adjustment subsumes risk items that are believed to be correlated under one risk factor. The resulting risk factors are assumed to be statistically independent, except for the factor for asset risks. The risk factors are then combined by taking the square root of the sum of each squared risk factor. ${ }^{15}$ It assumes independence between risk categories and is therefore not able to take linear and non-linear dependence into account.

\footnotetext{
${ }^{36}$ Embrechts et al. (2002).
} 
Although most recent changes to the RBC system include scenario analyses for market and interest rate risks within the life insurance formula, ${ }^{37}$ it still does not account for interdependencies between premium and reserve risks as well as between assets and underwriting risks. ${ }^{38}$

Under the own risk and solvency assessment guidelines of the NAIC, quantitative assessments of the risk categories have to include scenario analyses and appropriate measurement techniques on the entity and the group level. ${ }^{22}$ Furthermore, the ORSA guidelines require a prospective solvency assessment including assessment of the projected economic capital and regulatory capital requirements, given the current risk situation and surplus capital. This should include any risks an entity is exposed to due to its group membership.

The broad guidelines under the ORSA are, however, not detailed enough to guarantee thorough standard capital charges that adequately display potential risk interdependencies. Furthermore, the risk assessment under ORSA, once enforced, will be unique to each entity, reflecting its specific business situation, and is therefore no replacement for an adequate and thorough calculation technique for standardised minimum capital charges, as specifically required by the IAIS (see above). Consequently, one has to base the judgement on the RBC standard formula, which is not able to fulfil criterion 1 .

In order to compute the solo target capital of an insurance company, the SST standard model for market risk uses the change in 79 preset risk factors to measure the change in risk-bearing capital. ${ }^{39}$ The random vector of the changes in risk factors is assumed to be multivariate, normally distributed and linearly correlated. However, the model accounts for the fact that risk factor changes might often exhibit skewness and excess kurtosis by requiring an additional scenario analysis. These scenarios constitute stresses to several risk factors and can be translated into changes in the RBC. ${ }^{23}$ Consequently, a distribution function for each scenario can be calculated, and the scenarios as well as the standard case of a normal year are summed up to an aggregate cumulative distribution function which is no longer normally distributed but exhibits fat tails.

With respect to the model calibration, the risk factors and their pairwise correlation of the standard model for market risk have to be estimated by the insurers according to the latest 10-year data on pre-specified, well-known indices. This ensures a flexible parameter calibration of a model that is grounded on empirical actualities.

Furthermore, the Swiss regulator encourages insurers to develop their own, more sophisticated internal model that might be better able to capture the insurers' specific financial data, for example, by taking other distributional assumptions into account or by defining additional scenarios. ${ }^{23}$

Concerning the qualitative requirements, the Swiss provisions on risk management and internal control require, inter alia, appropriate measures to identify, assess and

\footnotetext{
37 Cummins and Phillips (2009).

${ }^{38}$ Casualty Actuarial Society (CAS) (2012).

${ }^{39}$ FINMA (2010b).
} 
report the significant risks of the companies. ${ }^{40}$ Also, the calculation methods applied have to be reviewed regularly and must take current scientific changes into account.

To sum up, the SST's standard model ensures an appropriate assessment of risk dependencies and an adequate recognition of tail dependence by incorporating scenario analysis into an empirically well-grounded and flexible solvency model.

According to the fifth Quantitative Impact Study on Solvency II of the European Insurance and Occupational Pensions Authority EIOPA (the former Committee of European Insurance and Occupational Pension Supervisors), the empirically calibrated stress factors that are used to calculate the overall SCR of the standard formula of Solvency II guarantee a solvency level of a 99.5 per cent value at risk. ${ }^{33}$ Through this, EIOPA aims to generate capital charges that are stable with regard to different risk dependencies under stressed financial conditions. ${ }^{33}$

Although linear correlation techniques are used to aggregate different risks and risk modules, EIOPA points out that the calibration of stress factors is carried out on the basis of extreme value analysis, where necessary, and is therefore able to account for fat tails. $^{41}$

In contrast to the SST, the static standard formula of Solvency II does not offer a framework that is able to reflect new market information by readjusting its parameter settings according to the latest available market data. This is a clear disadvantage of the standard formula as new political situations and changing economic structures can affect the dependencies between different risk categories of an insurer in significant ways.

Under Pillar II, qualitative requirements can be found that demand to adequately identify and measure the risks and their interdependencies on the company-level and on an aggregate group level (see, e.g., Articles 44 and $45^{12}$ ). Furthermore, Article 110 of the Solvency II Directive permits the supervisory authority to require the exchange of some of the solvency parameters in case the standard formula is not able to adequately reflect the specific risks of the insurer. ${ }^{12}$ Those second pillar supplements therefore seem to ensure the correct capital endowments.

However, since under normal circumstances European (re)insurers are allowed to use the standard formula to calculate the SCRs and MCRs, the disadvantage of a static capital assessment under Solvency II remains for a multitude of companies.

\section{Fungibility of capital and recognition of diversification effects}

Diversification is a key feature of modern risk management to reduce overall risk by exposing one's portfolio to a variety of risk sources rather than just a few. Within the context of regulation, diversification can be classified into four categories ${ }^{42}$ : the diversification within one type of risk, between risk types, across legal entities of an insurance group, and between regulatory jurisdictions. The former two categories of diversification should be accounted for within the solo supervision, whereas all four categories should be recognised through group supervision. As we already discussed

\footnotetext{
${ }^{40}$ FOPI (2007).

${ }^{41}$ CEIOPS (2010).

${ }^{42}$ CRO Forum (2005).
} 
the former two categories of diversification effects within the last section, we will now focus on the latter two.

With regard to the recognition of diversification effects within an international insurance group, the extent to which assets and risks are fungible between different group members becomes an important issue. There may be conflicts of interest as well as various legal constraints restricting the transferability of assets and risks and the fungibility of capital ${ }^{1}$ which is why the degree of capital mobility has to be taken into account within a group solvency assessment.

A pure, consolidated group-wide capital approach implicitly assumes full fungibility of capital and risks leading to a maximum diversification effect on the group level that significantly reduces group capital requirements. ${ }^{1}$ In practice, however, the transferability of assets and risks is usually restricted, especially when one or more group members experience financial distress. ${ }^{43}$ The IAIS therefore points out that, under a consolidated group solvency approach, it is important to consider the impediments to free intra-group capital flows and the transfers of assets and risks by means of stress tests. ${ }^{1}$

By contrast, an approach to group supervision with a legal entity focus is generally able to take the actual constraints to transferability of assets and risks and fungibility of capital into account. In order to do so, the approach has to assess the interactions within an insurance group in all its financial states, in a qualitative and quantitative way.

The NAIC solo-plus framework (displayed in section "Solo-plus approach of the NAIC") fits into the legal entity group solvency approaches that take limited fungibility and transferability into account. As already mentioned, it constitutes a solo approach that focuses on the legal entity, but requires group-level information, as well. Regarding intra-group transactions, the Insurance Holding Company System Regulatory Act forces the insurer to provide the supervisor with information on CRTIs such as intra-group loans, guarantees, reinsurance agreements, management agreements, as well as exchanges of assets. ${ }^{19}$ The ORSA requires, inter alia, all U.S.-based legal entities of an insurance holding company system to conduct an annual qualitative and quantitative analysis of their solvency situation on the group level. ${ }^{44}$ With regard to the qualitative assessment, the NAIC requires to take account of all intra-group transactions and diversification effects as well as restrictions on the capital mobility within the holding company system. Within the quantitative group-wide solvency assessment, the draft suggests eliminating intra-group transactions, either by applying a consolidated method in which all CRTIs are cancelled out or by adjusting for intragroup holdings when summing up capital resources and requirements under an aggregation method. ${ }^{44,22}$ However, it does not require the consideration of CRTIs in the sense of imposing minimum capital requirements for the group that result, when violated, in regulatory interventions. ${ }^{44}$ It needs to be critically noted that, in turn, diversification effects cannot be recognised within the standard RBC formula.

The SST group structure model can also be categorised under the legal entity approaches. Here, only the economically available capital of a subsidiary is considered

\footnotetext{
43 Keller (2007).

${ }^{44}$ NAIC (2011a).
} 
fungible, that is its economic value less the cost of capital. ${ }^{29}$ Furthermore, the fungibility is only recognised when legally binding capital transfer contracts are in place. Similarly, the transferability of assets and risks must be ensured by a legal agreement between the group members in order to be taken into consideration for the group solvency test. In contrast to the U.S. solo-plus approach, the SST group structure model does not only rely on the declaration of intra-group transfers, but also requires the consideration of these transfers within the quantitative capital requirements of the solvency test. The impact of a CRTI on the transferring and the benefiting company's risk situation has to be assessed, and the change in solvency capital charges, due to the transfer, has to be quantified. ${ }^{29}$ Therefore, Switzerland's group approach is able to appropriately assign and recognise diversification effects.

As for the group solvency assessment under Solvency II, we already explained in section "Solvency II Directive on group solvency assessment" that it belongs to the consolidated group models. The standard accounting consolidation-based method initially incorporates the problem of implicitly assuming full fungibility of capital and transferability of assets and risks. However, as pointed out by EIOPA, the current Directive plans to develop requirements under Pillars II and III, demanding scenario analyses on the impact of limited fungibility of capital due to certain stress events for all members of the insurance group as well as a strategic plan on how to deal with financial distress in one or several entities. ${ }^{35}$ Additionally, the group supervisor is expected to assess the insurance group's management of free capital under stress scenarios such as fungibility constraints.

Under the alternative deduction and aggregation method, diversification effects on the group level are not recognised. Here, intra-group transactions are not implicitly eliminated as within the standard approach. In order to recognise diversification effects under this method, capital and risk transfers should be recognised within a separate calculatory step. The assessment of intra-group transactions is placed within the qualitative requirements for governance and risk management under Pillar II. The Solvency II Directive establishes that the (re)insurance company at the head of the group has to report on a regular basis all noteworthy inter-linkages between the group's legal entities. ${ }^{12}$ Having received the necessary information and after consulting the supervisory authority, the assigned group supervisor has to identify the type of CRTI and its impact on the financial situation of the insurance group.

In summary, we can see that the aforementioned diversification benefits across entities of an insurance group are taken into account under Solvency II only within the qualitative requirements of Pillars II and III. Unless the finalised group approach, which is expected in 2013, considers intra-group transactions and limited fungibility additionally within Pillar I, calculating quantitative group capital requirements, the approach might overestimate the fungibility of capital and therefore the financial health of the insurance group.

\section{Prevention of multiple capital gearing}

Group-wide capital standards need to prevent any intra-group generation of capital so that the financial health of the individual companies and the insurance group as a whole is not overestimated. ${ }^{1}$ This internal capital creation, called "multiple capital 
gearing", takes place when the same regulatory capital is used to cushion risks in more than one legal entity of the group. ${ }^{45}$

A group solvency model that is based on consolidated accounts calculates, by definition, consolidated capital resources and capital requirements from which intragroup transactions are already subtracted. Thus, such an approach ensures that multiple capital gearing cannot occur on the group level.

In contrast, group solvency models with a legal entity focus consider the applied CRTIs within an insurance group when determining group capital charges. In order to prevent multiple gearing of capital, they need to take each relevant transaction and participation between group members into account and value each of them consistently with the market. ${ }^{1}$

As already mentioned in the previous subsection, the NAIC's solo-plus approach so far does not require considering intra-group transactions within the standard formulas to calculate minimum capital charges. However, ORSA will require a qualitative as well as quantitative group-wide solvency assessment. This implies that the NAIC's group approach will be able to account for multiple capital gearing by eliminating intra-group transactions, as specified in more detail in the previous sub-section. Thus, the solo-plus approach, once revised and extended, will be able to control capital gearing.

Under the SST group structure model, the mechanism to avoid multiple capital gearing is twofold: Firstly, an insurance group is modelled as a parent-subsidiary constellation in which the market value of the subsidiaries is an asset to the parent company and the risks of the subsidiaries are therefore taken into account within the capital requirement for the parent company. ${ }^{1}$ Secondly, by considering every capital and risk transfer between group members quantitatively. Therefore, capital resources and capital requirements are increased/decreased for each legal entity, appropriately. Regarding the qualitative requirements, an insurance group under Swiss regulation has to semi-anually prepare an SST report on the group level. ${ }^{25}$ Consequently, the SST group model fulfils the third criterion.

Articles 222 and 223 of the Solvency II Directive deal with the elimination of multiple capital gearing and intra-group capital creation. ${ }^{12}$

They require the exclusion of the asset values of participating or related companies that simultaneously constitute free capital qualifying for the solvency capital requirement of other legal entities of the group, whenever another calculation method than the consolidation-based method is applied. Furthermore, Article 223 establishes that the calculation of group capital charges is to ignore any eligible own funds for the SCR that are generated through "reciprocal financing" 46 between a participating company and another group member. ${ }^{12}$ Therefore, the Solvency II group framework is able to anticipate multiple gearing of capital.

\footnotetext{
45 Joint Forum on Financial Conglomerates, 1999.

46 According to the Solvency II Directive, "reciprocal financing" is assumed at least when an insurance company, or a related entity, grants loans to or holds stakes in another entity that, directly or indirectly, holds eligible capital for the SCR of the first company (see EC, 2009).
} 


\section{Avoidance of regulatory arbitrage and implementation of supervisory colleges}

Regulatory arbitrage is the opportunity to exploit differences in regulation between jurisdictions, regulated sectors or business divisions, to achieve capital or profit goals in the best possible way. ${ }^{1}$

The rationale behind the avoidance of regulatory arbitrage is, from a supervisory perspective, on the one hand, that it may entail risks because some countries require significantly lower levels of regulatory capital and the overall quality of supervision is considered insufficient from a European or North American point of view. On the other hand, the principle of regulatory consistency requires that a different regulatory treatment of the legal entities within an insurance group should be based on discrepancies in economic characteristics instead of differences in the legal structure. ${ }^{1}$ In order to prevent regulatory arbitrage several aspects have to be considered. ${ }^{1}$

In general, the same regulatory regime should be applied to all entities of a consolidated group. However, for some entities this might not be feasible as they might be subject to a foreign regulatory regime. Under such circumstances, a capital deduction or a restriction of capital and risk transfers to these particular entities should be applied.

Moreover, a successful harmonisation of solvency frameworks on an international level is crucial. It is important for the supervisors of the different legal entities within an insurance group to closely cooperate and share information that is relevant for the group's solvency. ${ }^{1}$ In this context, the IAIS suggests to designate a group-wide supervisor for each insurance group who is in charge of coordinating the cooperation and assessment of group-wide solvency as well as the risk management, risk reporting and allocation of capital. ${ }^{47}$ Furthermore, it is argued that an important tool to coordinate regulatory activities and cooperation is the establishment of a college of supervisors. ${ }^{48}$ These supervisory colleges provide a forum of communication and knowledge transfer.

Prior to the SMI, U.S. group supervision has focused on the holding company and its national insurance subsidiaries. The amendments to the Insurance Holding Company System Regulatory Act of 2010 extend the regulatory authority to all group members that potentially contribute to enterprise risk. ${ }^{49}$ This implies that the U.S. group supervisors get additional access to information on non-insurance entities as well, for example, through the enterprise risk report of the holding company. As every domestic insurer has to notify the group supervisor of any material intra-group transaction of the insurance holding company system, the group supervisor has the power to control and restrict the inter-group risk and capital flows. ${ }^{19}$

The first meeting of a supervisory college in the U.S. took place in 2008. It mainly dealt with agreements on information sharing and the assessment of common supervisory goals. ${ }^{50}$ Since that time, the NAIC has continued to develop the regulation tool of supervisory colleges. ${ }^{50}$ The revised Insurance Holding Company System

\footnotetext{
${ }^{47}$ IAIS (2008a).

${ }^{48}$ IAIS (2009a).

${ }^{49}$ EIOPA (2012).

${ }^{50}$ NAIC (2009b).
} 
Regulatory Act of 2010 provides the chief insurance regulatory official with the power to participate in a supervisory college and to cooperate with foreign or other federal or state regulators in order to assess the financial, legal and regulatory position of any domestic insurance company that is part of an international insurance holding company system. ${ }^{19}$ However, it prohibits delegation of the supervisory power of the insurance commissioner over the legal entities and affiliates located within its jurisdiction to the supervisory college. Furthermore, the NAIC serves as a coordinator of supervisory colleges across U.S. states. However, it does not carry out a mediator role in case of unresolvable disputes, as U.S. states retain the regulatory power over each legal entity that they grant license. ${ }^{49}$

According to the definition of an insurance group, Swiss supervision ranges over foreign subsidiaries as well as non-insurance entities as long as the control exercising company is based in Switzerland. ${ }^{27}$ The Directive of Internal Business Transactions demands that insurance groups report all significant internal transactions to FINMA. ${ }^{51}$ Furthermore, as discussed in the section "Fungibility of Capital and Recognition of Diversification Effects", the group structure model requires the consideration of every legally binding CRTI within the calculation of the quantitative capital requirements. This ensures the correct recognition of potential restrictions in the transferability of capital and risks. ${ }^{43}$

Switzerland's FINMA stays in close contact to foreign supervisory authorities such as EIOPA, the Committee of European Banking Supervisors (CEBS), the European Commission (EC), as well as the U.K. and U.S. regulatory authorities. Furthermore, it is actively involved in international committees such as the IAIS and the Financial Stability Board (FSB). FINMA heads and takes part in a number of supervisory colleges and organises crisis management for the Swiss banking and insurance industry. ${ }^{52}$ As a host supervisor, FINMA ensure effective information exchange and cooperation. ${ }^{53}$ However, it does not determine a formal dispute resolution mechanism.

In its publication on the lessons learned from the subprime financial crisis, EIOPA points out that in order to avoid regulatory arbitrage across sectors, it aims to set the stress factors of the different sub-modules of the market risk module such that a crosssectional consistency with the banking industry is given. ${ }^{54}$ In line with the two other frameworks, Solvency II requires the insurance holding companies to prepare an annual report on significant intra-group transfers and every important transaction within the group is subject to review by the group supervisor (see Article $245^{12}$ ).

With respect to arbitrage opportunities across jurisdictions, ${ }^{12}$ Articles 248 to 259 of the Solvency II Directive introduces the tools of group supervisors and supervisory colleges. It requires that the authorities, involved in the supervision of a particular insurance group, closely cooperate and share information, without bias towards the tasks they have to fulfil with respect to the solo supervision. In case of unsolvable disagreements within the supervisory college of a particular group, it states that

\footnotetext{
51 FINMA (2008c).

52 FINMA (2010a).

${ }^{53}$ FINMA (2012).

${ }^{54}$ CEIOPS (2009b).
} 
any member of the supervisory college is allowed to approach EIOPA for advice. Furthermore, Article 249 requires the supervisors of the different legal entities of an insurance group to immediately call for a meeting whenever the SCR or MCR of a group member is breached or when the group capital requirements cannot be met in full.

Apart from the cooperation between the insurance supervisors of individual entities of an insurance group, Solvency II requests close collaboration between an insurance supervisor and any supervisory authority of a credit institution or an investment firm that is related to or has a common participating company as the insurer (see Article $252^{12}$ ). In line with these requirements, Article 12 of the Financial Conglomerates Directive of the EU requires supervisors of the entities of a financial conglomerate to exchange all relevant information upon request. ${ }^{55}$ Additionally, the 2011 amendment to the Financial Conglomerates Directive obliges the supervisors in Article 7 to agree upon common supervisory approaches for financial conglomerates. ${ }^{56}$ This includes the competence to apply the tools of all directives concerning insurance, banking and securities.

The issue of regulatory arbitrage and the harmonisation of different regulatory frameworks is a difficult task. As discussed above, the regulatory authorities of the United States, Switzerland and the European Union are currently taking steps to enhance international cooperation between insurance supervisors. Notwithstanding these efforts, in the long run, globally binding minimum capital standards will be needed in order to contribute to the prevention of future global financial crises. Additionally, the regulatory frameworks need to stay flexible enough to concede effective implementation on a national level. ${ }^{52}$ To date, this common goal has not yet been achieved.

\section{Scope of group supervision and treatment of nonregulated entities}

The rapid development of the financial industry over the past two decades has contributed to an increasing complexity in the structure of financial conglomerates and insurance groups. This has brought forth, inter alia, the formation of insurance groups that are made up of a multitude of different legal entities, including "nonregulated entities". According to the definition of the IAIS, ${ }^{57}$ a nonregulated entity is a legal entity of an insurance group that is either a "nonoperating holding company" (NOHC) or an operating entity that is not subject to any form of direct supervisory activities ("nonregulated operating entity" (NROE)).

The existence of nonregulated entities additionally complicates the assessment of capital requirements for insurance groups. For a group solvency approach to ensure transparency and to appropriately measure the nature, scale and interdependencies of risks faced by the insurance group, it is important to establish mechanisms to provide for an adequate handling of these entities. ${ }^{1}$

\footnotetext{
${ }^{55} \mathrm{EC}(2002)$.

${ }^{56} \mathrm{EC}(2011 \mathrm{a})$.

${ }^{57}$ IAIS (2010)
} 
The IAIS guidance paper on the treatment of nonregulated entities in group-wide supervision lists several risks that may be caused by the existence of NOHCs and NROEs. ${ }^{57}$

Some of those risks are related to the issue of corporate governance, such as a lack of transparency and inappropriate disclosure policies, as well as conflicts of interest between the different stakeholders of the group. Furthermore, regulatory arbitrage is an issue, as nonregulated entities can be used to avoid capital requirements and to engage in business activities that are not permitted for a regulated group member. Other related risks are financial contagion and reputational risks. NROEs might face considerable amounts of risks without providing an appropriate capital buffer. These risks might be directly transferred to other entities of the group through CRTIs or might be carried over indirectly by adversely affecting the reputation of the whole insurance group.

In order to effectively deal with nonregulated entities, the IAIS therefore defines certain key characteristics a good group solvency approach needs to entail ${ }^{57}$ :

(a) Supervisors should have a comprehensive understanding of the insurance group's organisational structure, including the activities of nonregulated entities and their influence on other regulated entities' risk exposure.

(b) In order to avoid regulatory arbitrage, enhance the harmonisation of regulatory frameworks, and provide enough flexibility to react to new risks, supervisors that are engaged in the same insurance group should cooperate and exchange information across states, countries and sectors.

(c) Disclosure and transparency rules as well as a possibility to implement risk mitigation measures should certify the timeliness, pertinence, and reliability of information.

(d) The assessment of group capital requirements should take risk exposures from NROEs into account.

There is no explicit mention of how to treat nonregulated entities within insurance groups in the Insurance Holding Company System Regulatory Act as of 2010. However, when interpreted correctly, some of its provisions implicitly exhibit the key characteristics required above. As mentioned before, the U.S. regulatory framework provides for intra-group transactions within Section 5 of the Regulatory Act. ${ }^{19}$ Furthermore, the powers granted to the group supervisor, especially the permit to engage in supervisory colleges, provides the regulatory framework to react to supranational and group-wide risk exposures.

With regard to disclosure and transparency rules, the Regulatory Act requires to disclose any relevant information on changes in control of an insurance company, as well as information on any material transactions and interrelations between an insurer and its affiliates, within a pre-specified time period. ${ }^{19}$

Although the task force for the SMI (see section "solo-plus approach of the NAIC") suggests considering potential risk sources and contagion effects stemming from nonregulated entities, ${ }^{20}$ it does not plan to account for such effects within the quantitative capital requirements. ${ }^{17}$ This holds also true for risks indirectly transferred from nonregulated legal entities that can potentially result in undersized capital requirements. 
Therefore, key characteristic (d) is not quantitatively accounted for, under the NAIC group solvency approach.

The organisational structure and transactions of an insurance group that is subject to the Swiss solvency regulation are taken into account, qualitatively and quantitatively, through the granular group solvency model of the SST. The consideration of legally binding risk and transfer contracts between all group members includes interactions with nonregulated entities. Regarding key characteristic (b), the various efforts to enhance the cooperation with other international supervisors have already been referred to in the section "Avoidance of regulatory arbitrage and implementation of supervisory colleges".

Considering the disclosure of relevant and timely information on the solvency situation of a group, FINMA requires semi-annual reports on the current group SST results as well as the data from the two previous semesters. ${ }^{58}$ Apart from relevant information on risks concentrations and the risk management systems of the group members, the reports entail the group's target capital and risk-bearing capital that are computed on the basis of the solvency margins of all group members, including fictitious solvency margins for nonregulated entities preset by the Swiss Financial Market Supervisory Authority. ${ }^{58}$ In addition, Swiss law sets specific criteria for placing NOHCs under supervision in so far as to require adherence to certain corporate governance standards and the existence of appropriate risk management tools. ${ }^{57}$

The group structure model of the SST, therefore, is able to satisfy requirements (a) to (d) in full.

According to the Solvency II Directive of November 2009, the supervisory authorities should take all intra-group transactions and relationships between regulated and nonregulated entities of a group into account. ${ }^{12}$ Similar to the U.S. and Swiss regulatory authorities, the European Commission aims to increase the harmonisation of regulatory frameworks across countries and sectors (see the previous subsection).

Furthermore, key characteristic (c) of the IAIS guidance paper can be found in Articles 253-256 of the Solvency II Directive. They enforce, inter alia, the exchange of relevant and verified information between supervisors and require the disclosure of an annual report on the solvency situation of the insurance group as a whole. ${ }^{12}$

Finally, with regard to the group capital charges, nonregulated entities are taken into account by including notional SCRs into the calculation of the group's solvency capital requirement. The notional solvency requirement is the capital requirement an entity would need to fulfil when treated as a regulated entity under the particular sectoral rules. ${ }^{33}$ Hence, the group solvency approach of Solvency II possesses key characteristic (d) as well.

\section{Conclusion}

In most jurisdictions, supervision of insurance companies is still based on the solvency assessment of each legal entity. During the past decade, however, group-wide approaches have been developed to complement solo supervision so that the risks

\footnotetext{
${ }^{58}$ FINMA (2008a).
} 
Table 1 Summary of the group model comparison

\begin{tabular}{lccc}
\hline Criterion & $\begin{array}{c}\text { United States } \\
\text { of America }\end{array}$ & $\begin{array}{c}\text { Switzerland } \\
\text { European } \\
\text { Union }\end{array}$ \\
\hline $\begin{array}{l}\text { 1. Assessment of risk dependencies } \\
\text { 2. Fungibility of capital and recognition of diversification effects }\end{array}$ & $(\sqrt{ })$ & $\sqrt{ }$ & $(\sqrt{ })$ \\
$\begin{array}{l}\text { 3. Prevention of multiple capital gearing } \\
\text { 4. Avoidance of regulatory arbitrage and implementation of }\end{array}$ & $(\sqrt{ })$ & $\sqrt{ }$ & $(\sqrt{ })$ \\
$\quad \begin{array}{l}\text { supervisory colleges } \\
\text { Scope of group supervision and treatment of nonregulated } \\
\text { entities }\end{array}$ & $(\sqrt{ })$ & $\sqrt{ }$ & $\sqrt{ }$
\end{tabular}

$\times$ not fulfilled; $(\sqrt{ })$ partly fulfilled; $\sqrt{ }$ completely fulfilled.

and chances of a group membership for an insurance company can be assessed. Furthermore, the expansion of financial groups across countries increasingly requires supervisors to internationally cooperate with each other and to converge regulatory frameworks in order to prevent future global financial crises.

This paper gives an overview and a comparison of the group-wide solvency approaches of the United States, Switzerland and the European Union on the basis of a criteria catalogue that is in line with the group solvency issues specified by the IAIS's Issues Paper on Group-Wide Solvency Assessment and Supervision. ${ }^{1}$ Table 1 summarises the main findings of this comparison. A check mark indicates that the respective criterion is fulfilled, whereas a check mark in brackets indicates that the criterion is only partly fulfilled by the group approach. A cross signifies that the group model is not able to satisfy the criterion at hand.

The main results from our comparison can be summarised and interpreted as follows:

The U.S. system to group solvency is significantly inferior to the European group models of Switzerland and the European Union. It fails to take into account risk dependencies and can only partly fulfil the criteria of recognising diversification effects, avoiding regulatory arbitrage across jurisdictions, and does not consider potential contagion effects from nonregulated entities within its quantitative capital requirements. However, one has to keep in mind that the NAIC approach has been the last of the three frameworks to be revised and is still a work in progress. In particular, the U.S. Federal Insurance Office has not yet released its report on U.S. insurance regulation. Furthermore, in contrast to the EU and Swiss frameworks, it places less emphasis on the use of standardised capital requirements and attaches greater importance to the group ORSA tool and the insurance holding company systems' enterprise risk management. ${ }^{7}$ Nevertheless, the solo-plus approach of the United States will need further enhancements within the coming years in order to keep up with the regulatory developments in Europe.

Switzerland's group structure model, by contrast, is able to achieve the highest score with regard to the five group criteria. It therefore seems slightly superior to Solvency II in terms of appropriately assessing risk dependencies and with regard to the recognition of group synergies and diversification effects. Nevertheless, the Solvency II group model represents a solid capital assessment that incorporates the 
latest experiences with financial crises and the recent findings in risk management (e.g. the requirement of group-wide capital charges, the assignment of group supervisors to align the regulation of legal entities within an insurance group, as well as the allowance to develop internal group models).

Finally, with regard to the IAIS's goal to avoid regulatory arbitrage and to harmonise the national regulatory frameworks, U.S. and European supervisors are making efforts to cooperate more closely on an international basis. The goal of globally binding minimum capital standards as one possible answer to the increasing internationalisation of insurance groups (e.g. as discussed by FINMA ${ }^{52}$ ), however, is still a distant prospect.

\section{References}

Casualty Actuarial Society (CAS) (2012) 'CAS Research Working Party on Risk-Based Capital Dependencies and Calibration', Report 1 Overview of Dependencies and Calibration in the RBC Formula. 1, from www.casact.org.

Committee of European Insurance and Occupational Pension Supervisors (CEIOPS) (2009a) 'CEIOPS' advice for Level 2 implementing measures on Solvency II: Assessment of group solvency', from www.eiopa.europa.eu.

Committee of European Insurance and Occupational Pension Supervisors (CEIOPS) (2009b) 'Lessons learned from the crisis', from www.eiopa.europa.eu.

Committee of European Insurance and Occupational Pension Supervisors (CEIOPS) (2010) 'Solvency II Calibration Paper', from www.eiopa.europa.eu.

Cummins, J. and Phillips, R. (2009) Capital adequacy and insurance risk-based capital systems, working paper, from www.rmi.gsu.edu.

Darlap, P. and Mayr, B. (2006) 'Group aspects of regulatory reform in the insurance sector', Geneva Papers on Risk and Insurance - Issues and Practice 31(1): 96-123.

Eling, M. and Holzmüller, I. (2008) 'An overview and comparison of risk-based capital standards', Journal of Insurance Regulation 26(4): 31-60.

Embrechts, P., McNeil, A. and Straumann, D. (2002) 'Correlation and Dependence in Risk Management: Properties and Pitfalls', in M. Dempster (ed.) Risk Management: Value at Risk and Beyond, Cambridge: Cambridge University Press, pp. 176-223.

European Commission (EC) (1998) 'Directive 98/78/EC of the European Parliament and of the Council of 27 October 1998 on the supplementary supervision of insurance undertakings in an insurance group', Official Journal of the European Communities, from www.eur-lex.europa.eu.

European Commission (EC) (2002) 'Directive 2002/87/EC of the European Parliament and of the Council of 16 December 2002 on the supplementary supervision of credit institutions, insurance undertakings and investment firms in a financial conglomerate', Official Journal of the European Union, from www.eurlex.europa.eu.

European Commission (EC) (2009) 'Directive 2009/138/EC of the European Parliament and of the Council of 25 November 2009 on the taking-up and pursuit of the business of insurance and reinsurance (Solvency II)', Official Journal of the European Union, from www.eur-lex.europa.eu.

European Commission (EC) (2010) 'QIS5 technical specifications', from www.ec.europa.eu.

European Commission (EC) (2011a) 'Directive 2011/89/EU of the European Parliament and of the Council of 16 November 2011 amending directives 98/78/EC, 2002/87/EC, 2006/48/EC and 2009/138/EC as regards the supplementary supervision of financial entities in a financial conglomerate', Official Journal of the European Union, from www.eur-lex.europa.eu.

European Commission (EC) (2011b) “"SOLVENCY II": Frequently Asked Questions (FAQs)', from www.ec.europa.eu.

European Insurance and Occupational Pensions Authority (EIOPA) (2012) 'Request for the EU-U.S. Dialogue Project for Public Comment on the Technical Committee Reports; Comparing Certain Aspects 
of the Insurance Supervisory and Regulatory Regimes in the European Union and the United States', from https://eiopa.europa.eu.

Federal Assembly of the Swiss Confederation (2004) 'Insurance Supervision Act', from www.finma.ch.

Filipović, D. and Kupper, M. (2007) 'On the group level Swiss Solvency test', Bulletin of the Swiss Association of Actuaries 1(1): 97-115.

Filipović, D. and Kupper, M. (2008) 'Optimal capital and risk transfer for group diversification', Mathematical Finance 18(1): 55-76.

Holzmüller, I. (2009) 'The United States RBC standards, Solvency II and the Swiss Solvency test: A comparative assessment', The Geneva Papers on Risk and Insurance - Issues and Practice 34(1): 56-77.

International Association of Insurance Supervisors (IAIS) (2008a) 'Guidance paper on the role and responsibilities of a group-wide supervisor', from www.iaisweb.org.

International Association of Insurance Supervisors (IAIS) (2008b) 'Principles on group-wide supervision', from www.iaisweb.org.

International Association of Insurance Supervisors (IAIS) (2009a) 'Guidance paper on the use of supervisory colleges in group-wide supervision', from www.iaisweb.org.

International Association of Insurance Supervisors (IAIS) (2009b) 'Issues Paper on Group-wide Solvency Assessment and Supervision', from www.iaisweb.org.

International Association of Insurance Supervisors (IAIS) (2010) 'Guidance paper on the treatment of nonregulated entities in group-wide supervision', from www.iaisweb.org.

Joint Forum on Financial Conglomerates (1999) 'Supervision of financial conglomerates', from www.bis.org.

Keller, P. (2006) 'Draft: Modelling of groups and group effects', from www.finma.ch.

Keller, P. (2007) 'Group diversification', The Geneva Papers on Risk and Insurance-Issues and Practice 32(3): 382-392.

Luder, T. (2007) 'Modelling of risks in insurance groups for the Swiss Solvency test', Bulletin of the Swiss Association of Actuaries 1(1): 85-97.

National Association of Insurance Commissioners (NAIC) (2009a) 'Issues for consideration in the Solvency Modernization Initiative', from www.naic.org.

National Association of Insurance Commissioners (NAIC) (2009b) 'NAIC and state insurance regulators involved in the U.S. FSAP', from www.naic.org.

National Association of Insurance Commissioners (NAIC) (2009c) 'Risk-based capital — General overview', from www.naic.org.

National Association of Insurance Commissioners (NAIC) (2010a) 'Insurance Holding Company System Model Regulation with Reporting Forms and Instructions; Model \#450 8/5/10 — as adopted by Financial Condition (E) Committee', from www.naic.org.

National Association of Insurance Commissioners (NAIC) (2010b) 'Insurance Holding Company System Regulatory Act, Model \#440 08/05/10 - As Adopted by Financial Condition (E) Committee', from www.naic.org.

National Association of Insurance Commissioners (NAIC) (2010c) 'Memorandum, February 26, 2010', from www.naic.org.

National Association of Insurance Commissioners (NAIC) (2011a) 'Group Capital Assessment Proposal for U.S. Compliance with the International Association of Insurance Supervisors (IAIS) Insurance Core Principles (ICP) on Group Capital and to Observe Financial Sector Assessment Program Recommendations', from www.naic.org.

National Association of Insurance Commissioners (NAIC) (2011b) 'Own Risk and Solvency Assessment (ORSA) Guidance Manual', from www.naic.org.

National Association of Insurance Commissioners (NAIC) (2011c) 'Solvency modernization initiative Roadmap', from www.casact.org.

National Association of Insurance Commissioners (NAIC) (2011d) 'Solvency modernization initiative Update as of January 2011', from www.naic.org.

National Association of Insurance Commissioners (NAIC) (2011e) 'White Paper on High-Level Corporate Governance Principles for Use in U.S. Insurance Regulation', from www.naic.org.

Pfeiffer, T. (2008) 'The SST Group Structure Model', presentation at the prize ceremony of the Walter Saxer-Versicherungs-Hochschulpreis, Zurich, from www.finma.ch.

Swiss Federal Office of Private Insurance (FOPI) (2004) 'White Paper of the Swiss Solvency Test', from www.finma.ch. 
Swiss Federal Office of Private Insurance (FOPI) (2006) 'Technical Document on the Swiss Solvency Test', from www.finma.ch.

Swiss Federal Office of Private Insurance (FOPI) (2007) 'Directives on Corporate Governance, Risk Management, and the Internal Control System', from www.finma.ch.

Swiss Financial Market Supervisory Authority (FINMA) (2008a) 'Circular 2008/29 Internal Business Transactions Insurance Groups', from www.finma.ch.

Swiss Financial Market Supervisory Authority (FINMA) (2008b) 'Rundschreiben 2008/30 Solvabilität I Versicherungskonzerne', from www.finma.ch.

Swiss Financial Market Supervisory Authority (FINMA) (2008c) 'Swiss Solvency Test: Circular 2008/44 SST', from www.finma.ch.

Swiss Financial Market Supervisory Authority (FINMA) (2010a) 'Annual Report 2010', from www finma.ch.

Swiss Financial Market Supervisory Authority (FINMA) (2010b) 'Wegleitung zum SST-MarktrisikoStandardmodell', from www.finma.ch.

Swiss Financial Market Supervisory Authority (FINMA) (2012) 'FINMA Policy on Insurance Supervisory Colleges', from www.finma.ch.

The Chief Risk Officer Forum (2005) 'A Framework for Incorporating Diversification in the Solvency assessment of insurers', from www.thecroforum.org.

van Rossum, A. (2005) 'Regulation and insurance economics', The Geneva Papers on Risk and InsuranceIssues and Practice 30(1): 43-46.

Vaughan, T.M. (2009) 'The Implications of Solvency II for U.S. Insurance Regulation', from www.naic.org.

\section{About the Author}

Caroline Siegel is a post-doctoral research fellow and project leader at the Institute of Insurance Economics, University of St. Gallen, Switzerland. She holds a $\mathrm{PhD}$ in economics from the University of St. Gallen, Switzerland and a degree in business administration, majoring in accounting and finance, from the University of Passau, Germany. Her research interests include asset-liability management, risk management and the regulation of financial intermediaries. 